Retinopathy of prematurity

\section{ROP and neurodevelopmental disabilities}

\section{G E Quinn}

\section{The dilemma in premature babies}

$\mathrm{T}$ here are essentially three ways in which blindness from retinopathy of prematurity (ROP) can be prevented, including elimination of premature birth, changes in neonatal care, and improved detection and treatment of established sight threatening retinopathy. It is on the latter that the attention and efforts of the ophthalmic community have been focused, leaving the first two to the paediatricians, perinatologists, neonatologists, nurses, and others who care for these tiny babies. What Darlow et al have done in the paper in this issue of the BJO (p 1592) is direct our attention to the second possibilitythat is, neonatal care may be able to be altered to decrease the incidence of potentially blinding disease.

Darlow et al document a remarkable variability in the prevalence of severe ROP among the nurseries in the neonatal intensive care units in the Australian and New Zealand Neonatal Network. Such variability is generally expected when morbidity or mortality results are compared across centres, even in an essentially population based study that this report represents (the four tertiary paediatric care referral centres are excluded from the analysis reported by Darlow et al). The variability in such reports can usually be explained by a combination of several factors, including case mix, assessment of the primary outcome measure, viability considerations by neonatologists at the various centres, and variations in clinical practice. For example, the percentage of high risk deliveries may differ dramatically among nurseries, leading to more at-risk infants in one nursery than another. Smaller nurseries may also have greater variation in the incidence of severe ROP because of sampling variability. In addition, standardisation of outcome measures in multicentre studies represents a huge challenge and can seriously impact the perceived prevalence of severe disease.

Thanks to a large enough sample and novel analytical techniques, Darlow et al have been able to take into account many of the potential confounding variables using logistic regression models. They find that variability across nurseries in the rates of severe ROP requiring treatment is not explained by case mix, sampling, or outcome assessment, but rather is probably the result of clinical practice in the individual nurseries. In their analysis, they wisely chose to highlight the improvement in rates of serious ROP that could be reached if clinical practice was altered to achieve the "best practice" rates achieved in the top 20th percentile of the nurseries, rather than focusing on the "problem" nurseries. Using this systemwide approach to changes in clinical care would lower the rate of severe ROP to $5.9 \%$ in the top $20 \%$ of nurseries from the overall rate of $9.6 \%$. They estimate that 79 cases of severe ROP would have been prevented.

A major problem that arises when practice patterns are changed is that interventions aimed at decreasing the rate of one serious problem may increase the rate of another, equally serious problem. A very clearcut example of this was provided in the 1950s when oxygen was found to be the root cause of blinding ROP and its delivery markedly restricted. ${ }^{1}$ This led to an increase in mortality ${ }^{2}$ and spastic diplegia among premature babies, ${ }^{3}$ and it was estimated that 16 infants died from curtailed oxygenation for each case of blindness prevented. ${ }^{4}$ This observation has particular clinical relevance when evaluating possible changes in clinical care of premature babies, a population that has had an increased survival rate as a result of advances in perinatal and neonatal medicine over the past 20 years in countries with high levels of human development ${ }^{5}$; it is also a population in which we have only an evolving understanding of the developmental disabilities that are detected later in life. ${ }^{6-8}$ Since clinical care of the premature baby is directed broadly at prevention of illness, undernutrition, and infection during a time of rapid brain growth and development, it is not hard to postulate that systemwide changes in practice may differentially impact on the occurrence of cerebral palsy, visual and hearing impairments, behavioural and social problems, and learning difficulties. ${ }^{9}$ When considering changes in practice patterns, clearly the possible effect of any change must concentrate not only on survival, but also on lifelong disabilities that may occur in this vulnerable population.

Identifying and implementing practice pattern changes may decrease the prevalence of severe ROP and, with appropriate treatment, of blindness. However, most children being blinded from ROP do not live in countries with high levels of human development, but rather they are born in countries with middle levels of human development, where neonatal services are rapidly expanding and where limited resources may severely impact delivery of the highest levels of neonatal care.' Thus, the alterations in clinical practice that may arise from examining the "best practice" nurseries in Australia and New Zealand may have limited generalisability to the nurseries that care for the largest proportion of babies at risk of blindness because of severe ROP.

Br J Ophthalmol 2005;89:1547. doi: 10.1136/bjo.2005.077388

Correspondence to: G E Quinn, Pediatric Ophthalmology, 1st Floor, Wood Building, The Children's Hospital of Philadelphia, Philadelphia, PA 19104, USA; quinn@email. chop.edu

\section{REFERENCES}

1 Patz A, Hoeck LE, de la Cruz E. Studies on the effect of high oxygen administration in retrolental fibroplasia. Am J Ophthalmol 1952;35:1248-52.

2 Avery ME, Oppenheimer EH. Recent increase in mortality from hyaline membrane disease. J Pediatr 1960;57:553-9.

3 McDonald A. Cerebral palsy in children of very low birth weight. Arch Dis Child 1963;38:579-88.

4 Cross KW. Cost of preventing retrolental fibroplasias. Lancet 1973;2:954-6.

5 Tucker J, McGuire W. Epidemiology of preterm birth. BMJ 2004:329:675-8.

6 MacDonald H. Committee on Fetus and Newborn. Perinatal care at the threshold of viability. Pediatrics 2002;1 10:1024-7.

7 Colvin M, McGuire W, Fowlie PW. Neurodevelopmental outcomes after preterm birth. BMJ 2004;329:1390-3.

8 Hintz SR, Kendrick DE, Vohr BR, et al. Changes in neurodevelopmental outcomes at 18 to 22 months' corrected age among infants of less than 25 weeks' gestational age born in 1993-1999. Pediatrics 2005; 115:1645-51.

9 Gilbert C, Fielder A, Gordillo L, on behalf of the International NO-ROP Group, et al.

Characteristics of infants with severe retinopathy of prematurity in countries with low, moderate and high levels of development: Implications for screening programs. Pediatrics 2005; 115:e518-25. 
Deep lamellar keratoplasty

\section{Overcoming the technical challenges of deep lamellar keratoplasty}

\section{Yamada}

\section{With continued improvements in surgical technique it may become the procedure of choice}

Lis amellar keratoplasty was the first form of corneal transplantation -attempted, with a history over a century, and has been regarded mainly as a therapeutic technique. ${ }^{12}$ Lamellar grafting offers several advantages over penetrating keratoplasty, including the elimination of allograft rejection and the avoidance of intraocular complications. In addition, more donor cornea can be used in lamellar keratoplasty since the procedure does not require donor endothelium. This is particularly important in countries where donor corneas are scarce. However, the use of lamellar keratoplasty has been limited by difficulties such as irregularity and scarring of tissue interfaces, leading to poor visual outcomes compared with penetrating keratoplasty, ${ }^{1-3}$ as well as technical difficulties and prolonged operating time. Penetrating keratoplasty has thus been the most common corneal transplantation procedure for visual restoration for many years. Although penetrating keratoplasty has been shown to be effective and safe for most anterior segment pathologies, there are persistent long term risks such as endothelial failure and immunological graft rejection. ${ }^{4}$

Deep lamellar keratoplasty (DLK) is a logical step in the surgical management of corneal stromal opacification in the setting of functional endothelium. ${ }^{1}$ In DLK, pathological stroma is excised down to Descemet's membrane, and offers the promise of better visual outcomes compared with conventional lamellar grafting. Since this procedure was first reported by Arichila in 1985, several large case series have described favourable visual results after DLK. ${ }^{36} \mathrm{~A}$ report of 120 cases by Sugita and Kondo demonstrated that corrected visual acuity improved by 0.09 to 0.6 on average after DLK. ${ }^{6}$ Anwar and Teichmann reported that $89 \%$ of 181 eyes treated by DLK achieved visual acuity of 20/40 or better. ${ }^{3}$ More recently, Shimazaki and associates performed a randomised prospective trial of DLK versus penetrating keratoplasty, ${ }^{7}$ showing that visual function after DLK, as measured by corrected visual acuity, contrast visual acuity, the glare test, and corneal topography, was comparable to that achieved in penetrating keratoplasty. It should be noted that DLK was superior to penetrating keratoplasty in measures of operative morbidity such as continuous endothelial cell loss and intraocular complications. ${ }^{78}$ These results suggest that DLK is a safe alternative to penetrating keratoplasty in eyes without endothelial abnormalities. These promising findings regarding DLK underscore the importance of overcoming technical challenges such as achieving thorough stromal tissue excision without perforation of Descemet's membrane.

Deep lamellar keratoplasty is a logical step in the surgical management of corneal stromal opacification in the setting of functional endothelium

Most corneal surgeons have confronted the technical challenge of deep lamellar dissection and the attendant risk of puncturing Descemet's membrane during DLK. To facilitate the dissection of stromal tissue while reducing the risk of perforation, Arichila ${ }^{5}$ and Price ${ }^{9}$ employed an air injection technique to separate tissue planes. Sugita and Kondo ${ }^{6}$ and Amayem and Anwar $^{10}$ used hydrodelamination to separate the deep stromal fibres from Descemet's membrane. Manche and associates $^{11}$ used a hyaluronic acid for viscodelamination. These dissection based procedures appear to be useful both in the identification of stromal layers, and in the separation of stromal layers from Descemet's membrane. An alternative approach involves improving visualisation of the deep stromal layers during surgery. Balestrzzi et al ${ }^{12}$ used trypan blue to stain and visualise the posterior stromal fibres. Moore and associates $^{13}$ attempted to use an ocular endoscope to visualise the posterior corneal surface. However, despite all these efforts, perforation of Descemet's membrane remains common in DLK. Even experienced DLK surgeons have been reported to demonstrate a perforation rate of as high as $25 \% .{ }^{26}$ Sugita and Kondo $^{6}$ also reported that stromal tissue was incompletely removed in one third of cases. Thus, thoroughly baring Descemet's membrane without perforation has proved to be a difficult, time consuming, and elusive operative goal for most corneal surgeons.

When employing air, fluid, or viscoelastic injection to dissect Descemet's membrane from the stromal tissue planes, it is ideal to achieve complete separation of these tissue planes with a single injection. When this is achieved, as described by Anwar and Teichmann, ${ }^{3}$ a large bubble is formed, indicating perfect separation of tissue planes. However, this result is not always achieved, in large part because the proper depth of dissection is difficult to estimate. Melles and associates $^{14}$ described a technique for the visualisation of the posterior corneal surface by filling the anterior chamber with air. Through a scleral incision, a deep stromal pocket was created across the cornea, using the mirror image of a 30 gauge needle as a reference for dissection depth. Senoo and associates, in this issue of the BJO ( $\mathrm{p}$ 1597), describe another approach to determining the proper depth of dissection. A sclerocorneal flap, as is employed during trabeculectomy, is made, and direct microscopic visualisation is used to guide dissection of stromal tissues to the region directly overlying Descemet's membrane. The continued development of such techniques promises to make DLK easier, safer, and less time consuming.

Trends in keratoplasty have been changing over the past decade. Ocular surface reconstruction, consisting of limbal transplantation combined with amniotic membrane transplantation, has enabled us to improve the management of cicatrising diseases. ${ }^{15} 16$ Posterior lamellar keratoplasty, also referred to as deep lamellar endothelial keratoplasty, was developed for patients with endothelial dysfunction. ${ }^{2}{ }^{17}$ These procedures are based on the concept that only the pathological part of the cornea, such as the epithelium or endothelium, should be replaced by donor tissue, leaving the healthy portion of the host cornea intact. DLK is consistent with this paradigm, and can be viewed as a procedure designed to remove pathological stroma from healthy corneas. With continued improvements in surgical technique, including the advance described by Senoo and associates in this issue, DLK may become the procedure of choice for keratoplasty in most eyes without endothelial abnormalities. 
Br J Ophthalmol 2005;89:1548-1549. doi: 10.1136/bjo.2005.077396

Correspondence to: Masakazu Yamada, MD Division for Vision Research, National Institute of Sensory Organs, National Tokyo Medical Center, 2-5-1 Higashigaoka, Meguro-ku, Tokyo 152-8902, Japan; yamadamasakazu@ kankakuki.go.jp

The author has no proprietary interest in any materials in this manuscript.

\section{REFERENCES}

1 Aggarwal RK. Deep lamellar keratoplasty-an alternative to penetrating keratoplasty. Br J Ophthalmol 1997;81:178-9.

2 Terry MA. The evolution of lamellar grafting techniques over twenty-five years. Cornea 2000; 19:611-16.

3 Anwar M, Teichmann KD. Deep lamellar keratoplasty; surgical techniques for anterior lamellar keratoplasty with and without baring of
Descemet's membrane. Cornea 2002;21:374-83.

4 Thompson RW, Price MO, Bowers PJ, et al. Longterm graft survival after penetrating keratoplasty. Ophthalmology 2003;110:1396-402.

5 Arichila E. Deep lamellar keratoplasty dissection of host tissue with intrastromal air injection. Cornea 1985;3:217-18.

6 Sugita J, Kondo J. Deep lamellar keratoplasty with complete removal of pathological stroma for vision improvement. $\mathrm{Br} J$ Ophthalmol 1997;81:184-8

7 Shimazaki J, Shimmmura S, Ishioka M, et al Randomized clinical trial of deep lamellar keratoplasty vs penetrating keratoplasty. Am J Ophthalmol 2002;134:159-65.

8 Panda A, Bageshwar LMS, Ray M, et al. Deep lamellar keratoplasty versus penetrating keratoplasty for corneal lesions. Cornea 1999; 18:172-5.

9 Price F. Air lamellar keratoplasty. Refract Corneal Surg 1989;5:240-3.

10 Amayem AF, Anwar M. Fluid lamellar keratoplasty in keratoconus. Ophthalmology 2000; 107:76-80.
11 Manche EE, Holland GN, Maloney RK. Deep lamellar keratoplasty using viscoelastic dissection. Arch Ophthalmol 1999;117:1561-5.

12 Balestrazzi E, Balestrazzi A, Mosca L, et al. Deep lamellar keratoplasty with trypan blue intrastromal staining. J Cataract Refract Surg 2002;28:929-31.

13 Moore JE, Herath G, Sharma A. Endoscopic visualization to aid deep anterior lamellar keratoplasty. Eye 2004;18:188-91.

14 Melles GRJ, Lander F, Rietveld FJ, et al. A new surgical technique for deep stromal, anterior lamellar keratoplasty. Br J Ophthalmol 1999;83:327-33.

15 Tseng SC, Prabhasawat P, Barton K, et al. Amniotic membrane transplantation with or without limbal allografts for corneal surface reconstruction in patients with limbal stem cell deficiency. Arch Ophthalmol 1998;116:431-41.

16 Tsubota K, Satake Y, Ohyama M, et al. Surgical reconstruction of the ocular surface in advanced ocular cicatricial pemphigoid and Stevens-Johnson syndrome. Am J Ophthalmol 1996;122:38-52.

17 Melles GR, Eggink FA, Lander F, et al. A surgical technique for posterior lamellar keratoplasty. Cornea 1998; 17:618-26.

\section{Mouse models may provide new insight into the relation between cholesterol and age related macular degeneration}

J L Duncan

\section{With the goal of preventing vision loss from this disease, it is important to identify modifiable risk factors that may be targets for intervention}

A ge related macular degeneration (AMD) is the leading cause of severe vision loss among the elderly in the United States, Europe, and Australia. However, the cause of this blinding disease remains a topic of active investigation. Most agree the pathogenesis of AMD is multifactorial and that it results from the interaction of genetic, environmental and ageing effects. Evidence from population based studies has supported a role for heredity in the pathogenesis of AMD. Recent studies have identified a polymorphism in the gene for complement factor $\mathrm{H}$ which may be present in up to half of all white AMD patients. ${ }^{1-4}$ However, polymorphisms in this gene are also frequently found in Japanese ${ }^{5}$ and Chinese $^{6}$ populations, where AMD infrequently causes vision loss. Clearly, development of AMD depends on the interaction of genetic background with other, presumably environmental, factors.

With the goal of preventing vision loss from this disease, it is important to identify modifiable risk factors that may be targets for intervention. Some, but not all, epidemiological studies have identified an association between cardiovascular disease risk and AMD. ${ }^{7}$ Cigarette smoking, a well recognised risk factor for cardiovascular disease, is the most consistently demonstrated modifiable risk factor contributing to $\mathrm{AMD},{ }^{8}$ and its role in complement activation has been considered supportive evidence of the part played by complement factor $\mathrm{H}$ mutations. ${ }^{3}$ Recent case-control ${ }^{9}$ and prospective ${ }^{10}$ studies have identified elevated $\mathrm{C}$ reactive protein, an inflammatory biomarker associated with cardiovascular disease, as a risk factor for AMD and AMD progression. Systemic hypertension has been associated with neovascular $\mathrm{AMD}^{11}$ and a poorer response to laser therapy for choroidal neovascularisation (CNV) in patients with AMD. ${ }^{12}$ Some studies have found an association between markers of systemic atherosclerosis and $\mathrm{AMD},{ }^{13}{ }^{14}$ but other large population based studies have found no consistent association. ${ }^{11}{ }^{15}$ Increased dietary consumption of saturated fat, ${ }^{16}$ monounsaturated and polyunsaturated fat and vegetable fat ${ }^{17}$ and cholesterol ${ }^{16}$ has been associated with early and late AMD in various studies. Some recent studies have identified an association between use of cholesterol lowering medications, such as statins, and reduced risk of early or late $\mathrm{AMD}^{18-22}$ while others have found no such association. ${ }^{23-25}$ Although total serum cholesterol has been associated with neovascular AMD in a large case-control study, ${ }^{26}$ many large population based studies have found no association. ${ }^{82}$ Some studies have suggested an association between different lipoprotein polymorphisms and risk of AMD, including apoE, ${ }^{28} 29$ apo $\mathrm{B}$, and apo $\mathrm{Al}^{30}$ Certainly the relation between cardiovascular risk factors, lipid metabolism, and AMD remains confusing.

\section{The findings described in LDL receptor deficient mice may provide insight into the mechanism of early AMD}

Insight into the role lipid metabolism has in the development of early AMD has come from the study of preclinical models. Although no murine model exists that exactly replicates the phenotype seen in human AMD, studies have shown that $\mathrm{C} 57 \mathrm{Bl} / 6$ mice fed a high fat diet and briefly exposed to blue-green light develop basal laminar deposits, ${ }^{31}$ a histological feature of human eyes with AMD. ${ }^{32}$ Mice with null mutations in apoE have shown basal linear deposits and thickened Bruch's membranes, similar to findings in human eyes with AMD..$^{33}$ However, neither of these models develops choroidal neovascularisation or geographic atrophy, the stages 
of AMD associated with vision loss in patients, limiting our understanding of the mechanisms responsible for these sight threatening complications.

In this issue of the BJO ( $\mathrm{p}$ 1627), Rudolf and colleagues present novel information about mice with a null mutation for the low density lipoprotein (LDL) receptor, which have been studied as a murine model of atherosclerosis. After receiving a high fat diet, LDL receptor deficient mice develop membrane bound translucent particles within a significantly thickened Bruch's membrane, while control mice with normal LDL receptors show no Bruch's membrane abnormalities. The membrane bound translucent particles observed in the LDL receptor deficient mice resemble vesicles observed in histological sections of basal linear deposits and large drusen, findings specific for early AMD. ${ }^{35}$ Although plasma cholesterol is significantly elevated in LDL receptor deficient mice fed both normal and high fat diets, it is not clear from the present work that the changes in Bruch's membrane in LDL receptor deficient mice derive from plasma cholesterol rather than from an intraocular source. ${ }^{36}$ Further ultrastructural analysis of the lipid composition of Bruch's membrane in LDL receptor deficient mice, using previously described methods to preserve neutral lipids, ${ }^{36}$ may provide insight into whether these deposits result from elevated plasma lipid levels or an intraocular source. Such information may clarify the discrepancies noted between plasma lipid abnormalities and risk of AMD in epidemiological studies.

Of interest, the authors demonstrate immunohistochemical reactivity for vascular endothelial growth factor (VEGF) in the basal retinal pigment epithelial (RPE) cells, the outer plexiform layer, and the photoreceptor inner segments of LDL receptor deficient mice, which increased after the mice received a high fat diet. The authors state that no spontaneous CNV was observed in the mice studied despite high levels of VEGF expression. However, the mice in this study were investigated at 4 months of age. It will be interesting to observe LDL receptor deficient mice at senescent ages to determine if the changes described in Bruch's membrane progress with advanced age or are accompanied by the development of CNV or RPE atrophy. Other mutant mice with phenotypes similar to human AMD develop fundus and histological changes only after the age of 9 months, with geographic atrophy and CNV developing only after 16 months and 18 months of age, respectively. ${ }^{37}$
Even in the absence of correlates of late $\mathrm{AMD}$, the findings described in $\mathrm{LDL}$ receptor deficient mice may provide insight into the mechanism of early AMD. The fact that the mice develop abnormally thickened Bruch's membranes, similar to early AMD, and demonstrate VEGF upregulation suggests that ischaemia or oxidative stress occurs even in early stages of AMD, perhaps as a result of compromised diffusion from the choriocapillaris to the outer retina. LDL receptor deficient mice will serve as a useful model of early AMD and may allow investigators to determine the part abnormalities of cholesterol metabolism may play in its pathogenesis. Whether or not deficiencies in the LDL receptor are associated with AMD in humans, the ocular phenotype of LDL receptor deficient mice described in the present work should encourage investigators to study murine models of atherosclerosis with careful attention to the eyes.

\section{ACKNOWLEDGEMENTS}

This work was supported by a Career Development Award from Research to Prevent Blindness, New York, New York; grants EY00415 and EY02162 from the National Eye Institute, Bethesda, Maryland; and grants from the Bernard A Newcomb Macular Degeneration Fund and That Man May See, Inc, San Francisco, California, and the Foundation Fighting Blindness, Owings Mills, Maryland, USA.

Br J Ophthalmol 2005;89:1549-1551. doi: 10.1136/bjo.2005.077370

Correspondence to: Jacque L Duncan, MD, University of California, San Francisco, 10 Koret Way, K129, San Francisco, CA $94143-$ 0730, USA; duncanj@vision.ucsf.edu

Competing interests: none declared

\section{REFERENCES}

1 Klein RJ, Zeiss C, Chew EY, et al. Complement factor $\mathrm{H}$ polymorphism in age-related macular degeneration. Science 2005; 308:385-9.

2 Haines JL, Hauser MA, Schmidt S, et al. Complement factor $\mathrm{H}$ variant increases the risk of age-related macular degeneration. Science 2005;308:419-21.

3 Hageman GS, Anderson DH, Johnson LV, et al. A common haplotype in the complement regulatory gene factor $\mathrm{H}(\mathrm{HFl} / \mathrm{CFH})$ predisposes individuals to age-related macular degeneration. Proc Natl Acad Sci USA 2005; 102:7227-32.

4 Edwards AO, Ritter R 3rd, Abel KJ, et al Complement factor $\mathrm{H}$ polymorphism and agerelated macular degeneration. Science 2005:308:421-4.

5 Nakamura S, Ohue O, Sawaguchi A. Genetic polymorphism of human factor $\mathrm{H}$ (beta $1 \mathrm{H}$ globulin). Hum Hered 1990;40:121-6.

6 Tsunenari S, Higashi T, Kibayashi K, et al. Genetic polymorphism of human factor H (HF, beta $1 \mathrm{H}$ globulin) in Chinese Han population in northeast China. Jpn J Hum Gene 1992;37:145-8

7 Snow KK, Seddon JM. Do age-related macular degeneration and cardiovascular disease share common antecedents? Ophthalmic Epidemiol 1999;6:125-43.
8 Smith W, Assink J, Klein R, et al. Risk factors for age-related macular degeneration: pooled findings from three continents. Ophthalmology 2001:108:697-704.

9 Seddon JM, Gensler G, Milton RC, et al. Association between C-reactive protein and agerelated macular degeneration. JAMA 2004:291:704-10.

10 Seddon JM, George S, Rosner B, et al. Progression of age-related macular degeneration: prospective assessment of $C$ reactive protein, interleukin 6 , and other cardiovascular biomarkers. Arch Ophthalmol 2005; 123:774-82.

11 Hyman L, Schachat AP, He Q, et al. Hypertension, cardiovascular disease, and agerelated macular degeneration. Age-Related Macular Degeneration Risk Factors Study Group Arch Ophthalmol 2000;118:351-8.

12 Macular Photocoagulation Study Group. Laser photocoagulation for juxtafoveal choroidal neovascularization: five-year results from randomized clinical trials. Arch Ophthalmol 1994; 112:500-9.

13 van Leeuwen $\mathbf{R}$, Ikram MK, Vingerling JR, et al. Blood pressure, atherosclerosis, and the incidence of age-related maculopathy: the Rotterdam Study. Invest Ophthalmol Vis Sci 2003;44:3771-7.

14 Klein R, Klein BE, Tomany SC, et al. The association of cardiovascular disease with the long-term incidence of age-related maculopathy: the Beaver Dam Eye Study. Ophthalmology 2003; 1 10:636-43.

15 Tomany SC, Wang JJ, Van Leeuwen R, et al. Risk factors for incident age-related macular degeneration: pooled findings from 3 continents. Ophthalmology 2004;111:1280-7.

16 Mares-Perlman JA, Brady WE, Klein R, et al. Dietary fat and age-related maculopathy. Arch Ophthalmol 1995;113:743-8.

17 Seddon JM, Cote J, Rosner B. Progression of agerelated macular degeneration: association with dietary fat, transunsaturated fat, nuts, and fish intake. Arch Ophthalmol 2003;121:1728-37.

18 Hall NF, Gale CR, Syddall H, et al. Risk of macular degeneration in users of statins: cross sectional study. BMJ 2001;323:375-6.

19 McCarty CA, Mukesh BN, Guymer RH, et al. Cholesterol-lowering medications reduce the risk of age-related maculopathy progression. Med J Aust 2001;175:340.

20 McGwin G Jr, Owsley C, Curcio CA, et al. The association between statin use and age related maculopathy. Br J Ophthalmol 2003;87:1121-5.

21 McGwin G Jr, Xie A, Owsley C. The use of cholesterol-lowering medications and age-related macular degeneration. Ophthalmology 2005; 112:488-94

22 Wilson HL, Schwartz DM, Bhatt HR, et al. Statin and aspirin therapy are associated with decreased rates of choroidal neovascularization among patients with age-related macular degeneration. Am J Ophthalmo 2004; 137:615-24.

23 Klein R, Klein BE, Tomany SC, et al. Relation of statin use to the 5-year incidence and progression of age-related maculopathy. Arch Ophthalmol 2003;121:1151-5

24 Van Leeuwen R, Vingerling JR, de Jong PT. Risk of macular degeneration with statin use should be interpreted with caution. BMJ 2001;323:1308.

25 Van Leeuwen R, Vingerling JR, Hofman A, et al. Cholesterol lowering drugs and risk of age related maculopathy: prospective cohort study with cumulative exposure measurement. BMJ 2003;326:255-6.

26 Seddon JM, Ajani UA, Sperduto RD, et al. Dietary carotenoids, vitamins $A, C$, and $E$, and advanced age-related macular degeneration. Eye Disease Case-Control Study Group. JAMA 1994;272:1413-20.

27 Cruickshanks KJ, Hamman RF, Klein R, et al. The prevalence of age-related maculopathy by geographic region and ethnicity. The Colorado Wisconsin Study of Age-Related Maculopathy. Arch Ophthalmol 1997;115:242-50.

28 Klaver CC, Kliffen M, van Duijn CM, et al. Genetic association of apolipoprotein $\mathrm{E}$ with age-related macular degeneration. Am J Hum Genet 1998;63:200-6 
29 Simonelli F, Margaglione $M$, Testa $F$, et al. Apolipoprotein $\mathrm{E}$ polymorphisms in age-related macular degeneration in an Italian population. Ophthalmic Res 2001;33:325-8.

30 Nowak M, Swietochowska E, Marek B, et al Changes in lipid metabolism in women with agerelated macular degeneration. Clin Exp Med 2005;4:183-7.

31 Cousins SW, Espinosa-Heidmann DG, Alexandridou $A$, et al. The role of aging, high fat diet and blue light exposure in an experimental mouse model for basal laminar deposit formation. Exp Eye Res 2002;75:543-53.

32 Green WR. Histopathology of age-related macular degeneration. Mol Vis 1999;5:27.

33 Dithmar S, Curcio CA, Le NA, et al. Ultrastructural changes in Bruch's membrane of apolipoprotein E-deficient mice. Invest Ophthalmol Vis Sci 2000;41:2035-42.

34 Ong JM, Zorapapel NC, Rich KA, et al. Effects of cholesterol and apolipoprotein $\mathrm{E}$ on retinal abnormalities in ApoE-deficient mice. Invest Ophthalmol Vis Sci 2001;42:1891-900.
35 Curcio CA, Millican CL. Basal linear deposit and large drusen are specific for early age-related maculopathy. Arch Ophthalmol maculopathy. Arch

36 Curcio CA, Presley JB, Millican CL, et al. Basal deposits and drusen in eyes with age-related maculopathy: evidence for solid lipid particles. Exp Eye Res 2005;80:761-75.

37 Ambati J, Anand A, Fernandez S, et al. An animal model of age-related macular degeneration in senescent Ccl-2- or Ccr-2deficient mice. Nat Med 2003;9:1390-7.

\section{Clinical Evidence-Call for contributors}

Clinical Evidence is a regularly updated evidence-based journal available worldwide both as a paper version and on the internet. Clinical Evidence needs to recruit a number of new contributors. Contributors are healthcare professionals or epidemiologists with experience in evidence-based medicine and the ability to write in a concise and structured way.

Areas for which we are currently seeking contributors:

- Pregnancy and childbirth

- Endocrine disorders

- Palliative care

- Tropical diseases

We are also looking for contributors for existing topics. For full details on what these topics are please visit www.clinicalevidence.com/ceweb/contribute/index.jsp

However, we are always looking for others, so do not let this list discourage you.

Being a contributor involves:

- Selecting from a validated, screened search (performed by in-house Information Specialists) epidemiologically sound studies for inclusion.

- Documenting your decisions about which studies to include on an inclusion and exclusion form, which we keep on file.

- Writing the text to a highly structured template (about 1500-3000 words), using evidence from the final studies chosen, within 8-10 weeks of receiving the literature search.

- Working with Clinical Evidence editors to ensure that the final text meets epidemiological and style standards.

- Updating the text every 12 months using any new, sound evidence that becomes available. The Clinical Evidence in-house team will conduct the searches for contributors; your task is simply to filter out high quality studies and incorporate them in the existing text.

If you would like to become a contributor for Clinical Evidence or require more information about what this involves please send your contact details and a copy of your CV, clearly stating the clinical area you are interested in, to CECommissioning@bmigroup.com.

\section{Call for peer reviewers}

Clinical Evidence also needs to recruit a number of new peer reviewers specifically with an interest in the clinical areas stated above, and also others related to general practice. Peer reviewers are healthcare professionals or epidemiologists with experience in evidence-based medicine. As a peer reviewer you would be asked for your views on the clinical relevance, validity, and accessibility of specific topics within the journal, and their usefulness to the intended audience (international generalists and healthcare professionals, possibly with limited statistical knowledge). Topics are usually 1500-3000 words in length and we would ask you to review between 2-5 topics per year. The peer review process takes place throughout the year, and out turnaround time for each review is ideally 10-14 days. If you are interested in becoming a peer reviewer for Clinical Evidence, please complete the peer review questionnaire at www. clinicalevidence.com/ceweb/contribute/peerreviewer.jsp 